\title{
APLICAÇÃO DE PARÂMETROS MORFOMÉTRICOS NA BACIA DO RIO IPANEMA: CONTRIBUIÇÕES À GEOMORFOLOGIA E MORFOESTRUTURA REGIONAL
}

\author{
Priscilla Emanoelle Claudino Silva ${ }^{(a)}$, Paulo de Tarso Barbosa Leite ${ }^{(b)}$, João Paulo da Hora \\ Nascimento $^{(\mathrm{c})}$, Kleyton de Araujo Monteiro ${ }^{(\mathrm{d})}$ \\ (a) Instituto de Geografia, Desenvolvimento e Meio Ambiente, UFAL, emanoelle.priscilla@gmail.com \\ (b) Instituto de Geografia, Desenvolvimento e Meio Ambiente, UFAL, tarso.geoufal@gmail.com \\ (c) Instituto de Geografia, Desenvolvimento e Meio Ambiente, UFAL, geografojoao@outlook.com \\ (d) Instituto de Geografia, Desenvolvimento e Meio Ambiente, UFAL, geokleython@ gmail.com
}

Eixo: 10. SISTEMAS GEOMORFOLÓGICOS: ESTRUTURA, DINÂMICAS E PROCESSOS

\begin{abstract}
Resumo
Para análise morfométrica de uma bacia de drenagem, é necessário fazer levantamentos de dados. O objetivo do presente trabalho é colaborar nos estudos da dinâmica geomorfológica do rio Ipanema que está localizado nos estados de Pernambuco e Alagoas, e é sub-bacia do rio São Francisco. Reviões bibliográficas e técnicas de geoprocessamento, auxiliaram na criação e intepretação dos mapas de Hierarquização Fluvial, método proposto por Strahler que ordena os canais da bacia que torna-se parâmetro para extrair informações sobre Densidade de Drenagem, utilizando índice proposto por Horton, que, no rio Ipanema demonstrou as áreas de maior e menor susceptibilidade geomorfológica da bacia de drenagem, e; Lineamentos de Drenagem, que apresentaram, a partir dos Diagramas de Rosetas, direção preferencial dos lineamentos nas direções NE e E-W, em conformidade com o contexto geotectônico regional.
\end{abstract}

Palavras chave: Análise morfométrica, rio Ipanema, hierarquia fluvial, densidade de drenagem, lineamentos de drenagem

\section{Introdução}

A análise morfométrica é um importante fator para compreensão de estudos geomorfológicos. A partir de levantamento dados, é possível utilizar parâmetros para facilitar estudos sobre estruturação de relevo e bacia de drenagem (LASZLO \& ROCHA, 2014). Entre os pioneiros de estudos geomorfológicos, estão Horton, Strahler e Christofoletti, que tinham o propósito de investigar a evolução da paisagem (ETCHEBEHERE et al., 2006). Os parâmetros utilizados, no presente trabalho, para análise morfométrica, foram: Hierarquização Fluvial, Densidade de Drenagem e Lineamentos de Drenagem na bacia do Rio Ipanema, afim de contribuir para a compreensão da dinâmica geomorfológica da bacia dos rio Ipanema. 


\section{Material e Métodos}

A bacia do Rio Ipanema possui nascente no macrodomo da Borborema, na Cimeira Estrutural Pernambuco-Alagoas. Com cabeceiras em regiões sub-úmidas no estado de Pernambuco e exutório no baixo São Francisco, no estado de Alagoas (Figura 1). Possui uma área de aproximadamente $6209,67 \mathrm{~km}^{2}$ percorrendo cerca de $139 \mathrm{~km}$ (MOREIRA FILHO, 2011).

Para desenvolver o presente trabalho, foram utilizadas revisões teóricas e metodológicas, e técnicas de geoprocessamento, em ambiente GIS, para extração de dados morfológicos e confecção dos mapas. Para extração de lineamentos foi utilizado o Modelo Digital de Elevação (MDE) que revela as feições lineares e, a partir da extração destes lineamentos, foram elaborados Diagramas de Rosetas para demonstrar a direção preferencial das drenagens analisadas.

A Hierarquização Fluvial, método proposto por Strahler, (MORAIS \& ALMEIDA, 2010), consiste em ordenar os principais canais de uma rede drenagem e seus afluentes, classificando como canais de primeira ordem, aqueles que são ligados diretamente à nascente e não possuem tributários; os canais de segunda ordem surgem da confluência de dois canais de primeira ordem e só recebem afluente destes, e assim sucessivamente (SANTOS \& BEHLING, 2014). Este parâmetro contribui com outros índices morfométricos, como Densidade de Drenagem que define-se como a relação do comprimento total dos rios ou canais com a área da bacia hidrográfica (CHRISTOFOLETTI (1969) apud SOUZA, \& PEREZ FILHO, 2015), índice proposto inicialmente por Horton (1945), e indica de susceptibilidade geomorfológica da bacia e o grau de dissecação topográfica (COLLARES, 2000), e; Lineamentos de Drenagem, que indicam influências nos cursos d'água ocasionadas por fatores estruturais e/ou reativações neotectônicas na região, sendo utilizados para identificar tais feições (SUMMERFIELD, 2000 apud NASCIMENTO E GARCIA, 2005).

\section{Resultados e Discussões}

A partir da hierarquização (Figura 2), foi possível classificar a drenagem da bacia do rio Ipanema em $5^{\mathrm{a}}$ ordem. A densidade de drenagem apresenta valores variando entre $0 \mathrm{~km} / \mathrm{km}^{2}$ a $6,98 \mathrm{~km} / \mathrm{km}^{2}$ nas baixas densidades, sinalizando a presença de terrenos mais permeáveis; e valores entre $10 \mathrm{~km} / \mathrm{km}^{2}$ e $18 \mathrm{~km} / \mathrm{km}^{2}$ nas densidades altas, indicando maior suscetibilidade geomorfológica (SANTOS \& LIMA, 2009).

Os Diagramas de Rosetas, separados por ordens dos canais, apresentaram a direção NE como sendo preferencial, havendo secundariamente a direção E-W, com alguns lineamentos ainda apresentando direção NW (Figuras 3 - 7); Estas direções estão conforme o contexto geotectônico regional (MAIA \& 


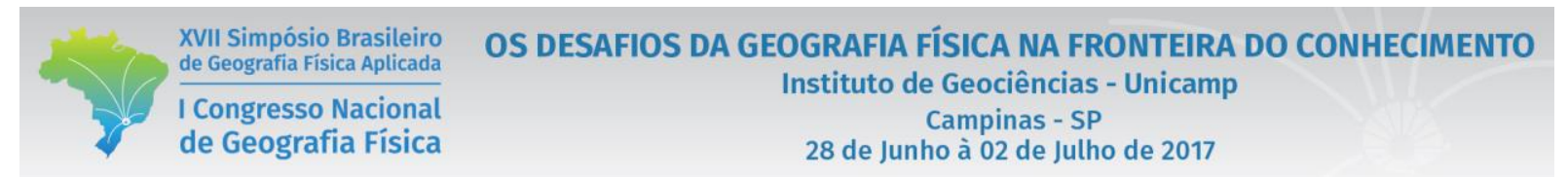

BEZERRA, 2014), devido a zonas de cisalhamento de direção E-W e ramificações de direção NE reativadas durante a ruptura do Pangea (MAGNAVITA, 1992 apud MONTEIRO et al. 2014).

\section{Considerações Finais}

A aplicação de geotecnologias mostrou-se eficaz no auxílio aos estudos morfométricos da bacia hidrográfica do rio Ipanema, tornando-a parâmetro para compreensão de processos hidrológicos e geomorfológicos. Com a Hierarquia Fluvial estabeleceu-se ordem entre os principais canais da rede de drenagem, e seus afluentes (MORAIS \& ALMEIDA, op cit), auxiliando no levantamento de análise morfométrica, dentre os quais, Densidade de Drenagem que evidencia áreas distintas quanto à vulnerabilidade à erosão e, Lineamentos de Drenagem para identificação de possíveis reativações neotectônicas. Os Diagramas de Rosetas evidenciaram as frequências das direções preferenciais dos lineamentos, que demonstraram conformidade com o trend regional em que a bacia de drenagem está inserida.

\section{Figuras}

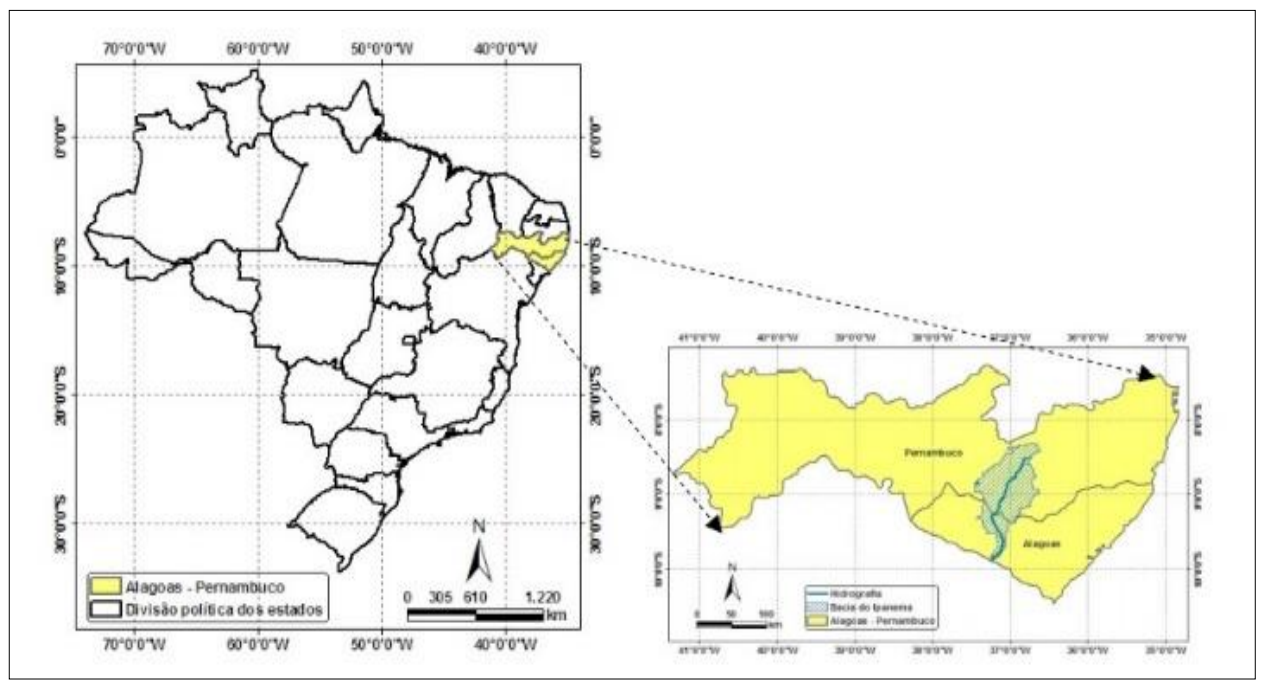

Figura 1 - Mapa de Localização da bacia do rio Ipanema

Fonte: MOREIRA FILHO, 2011 

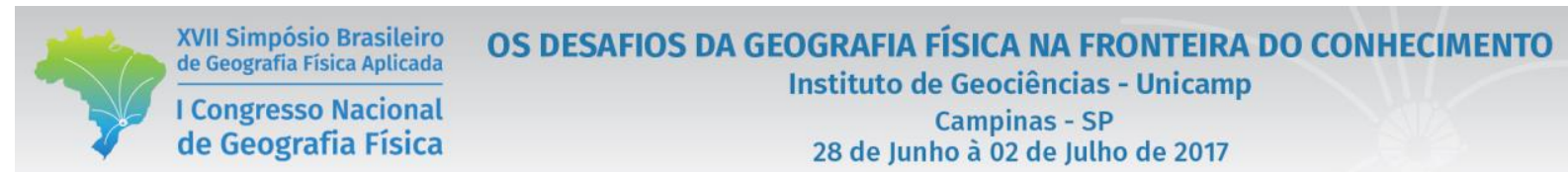

Figura 2 - Mapa de

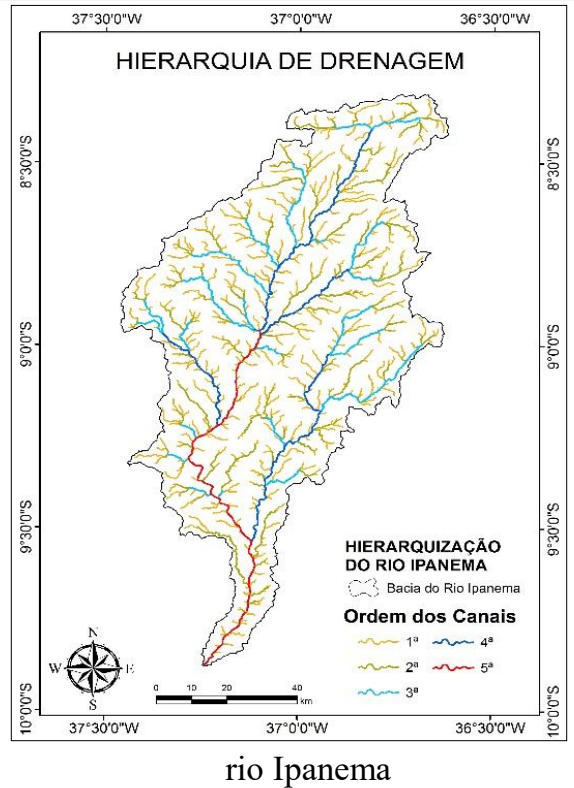

Hierarquização Fluvial da bacia do rio Ipanema

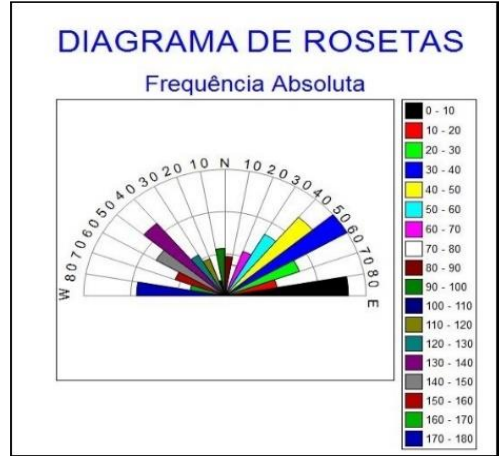

Figura 3 - Diagrama de Rosetas dos canais de $1^{\text {a }}$ ordem
DIAGRAMA DE ROSETAS
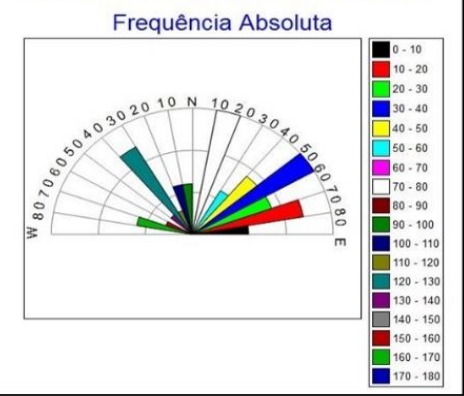

Figura 4 - Diagrama de Rosetas dos canais de $2^{\mathrm{a}}$ ordem
DIAGRAMA DE ROSETAS

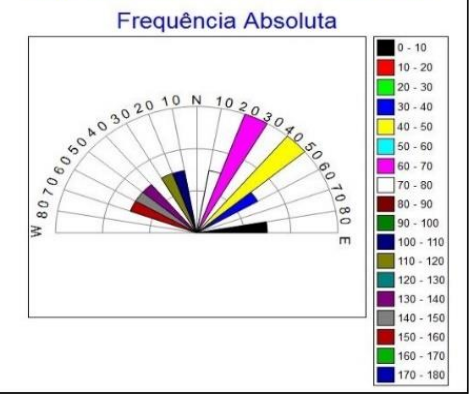

Figura 5 - Diagrama de Rosetas dos canais de $3^{\mathrm{a}}$ ordem

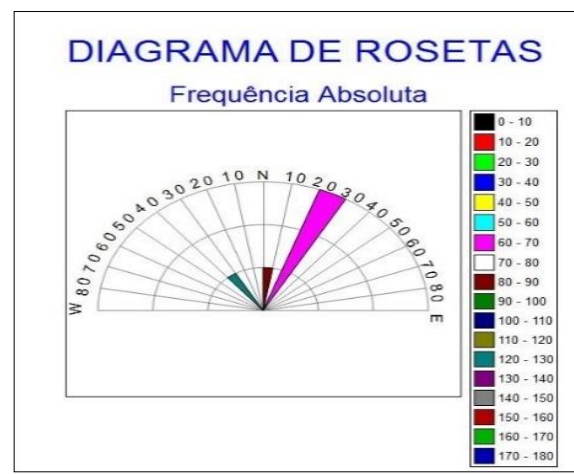

Figura 6 - Diagrama de Rosetas dos canais de $4^{\mathrm{a}}$ ordem

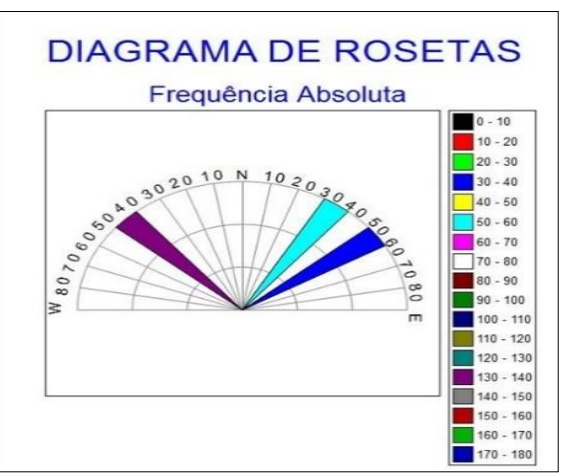

Figura 7 - Diagrama de Rosetas dos canais de $5^{\mathrm{a}}$ ordem 


\section{Bibliografia}

COLlares, E. G. Avaliação de Alterações em Redes de Drenagem de Microbacias como Subsídio ao Zoneamento Geoambiental de Bacias Hidrográficas: Aplicação na Bacia Hidrográfica do Rio Capivari - SP. Vol 1. Tese (Doutorado) - Escola de Engenharia de São Carlos, Universidade de São Paulo. São Carlos, 2000. p. xi.

ETCHEBEHERE, M. L. C. SAAD, A. R. SANTONI, G. CASADO, F. C. FULFARO V. J. Detecção de Prováveis Deformações Neotectônicas no Vale do Rio do Peixe, Região Ocidental Paulista, Mediante Aplicação De Índices RDE (Relação DeclividadeExtensão) em Segmentos de Drenagem. São Paulo, UNESP, Geociências, v. 25, n.3, 2006. p. 271-272.

LASZLO, M. J., ROCHA, P. C. Composição Hierárquica dos Canais Fluviais das Bacias Hidrográficas dos Rios Aguapeí e Peixe. Revista Geonorte, Edição especial 4, v.10, n.1, 2014. p.229. (ISSN 2237-1419).

MAIA, R. P. BEZERRA, F. H. R. Condicionamento Estrutural Do Relevo No Nordeste Setentrional Brasileiro. Universidade Federal do Ceará. Revista Mercator. v. 13, n. 1, 2014. p. 128-130.

MONTEIRO, K. A. TAVARES, B. A. C. CORRÊA, A. C. B. Aplicação do Índice de Hack do Rio Ipojuca para Identificação de Setores Anômalos de Drenagem e Rupturas de Relevo. São Paulo, UNESP, Geociências, v. 33, n. 4, 2014. p.618.

MORAIS, F., ALMEIDA, L. M. Geomorfologia Fluvial da Bacia Hidrográfica do Ribeirão Jaú, Palmas, Estado do Tocantins. Brazilian Geographical Journal: Geosciences and Humanities Research Medium, Uberlândia, v. 1, n. 2, 2010. p. 334.

MOREIRA FILHO, J. C. C. Modelagem Geográfica Tridimensional na Bacia Hidrográfica do Rio Ipanema, Uma Comparação Entre os Métodos de Triangulação e Inverso do Quadrado da Distância com Uso de SRTM. Anais XV Simpósio Brasileiro de Sensoriamento Remoto - SBSR, Curitiba, PR, Brasil, 2011, INPE p. 1295-1296.

NASCIMENTO, P. S. R. GARCIA, G. J. Compartimentação Fisiográfica para Análise Ambiental do Potencial Erosivo a Partir das Propriedades da Rede de Drenagem. Eng. Agríc., Jaboticabal, v.25, n.1, 2005. p.232.

SANTOS, V. S., BEHLING, A. A. Hierarquização da Rede de Drenagem da Bacia Hidrográfica do Rio Ibicuí, Localizada no Oeste do Estado do Rio Grande do Sul. Universidade Federal de Santa Maria, 2014. p. 2-6.

SANTOS, J. M. LIMA, K. C. Análise da Rede de Drenagem em Bacias Hidrográficas Tropicais: Bacia do Riacho Grande - Bahia/Brasil. Associação Portuguesa de Geomorfólogos, v. vi, apgeom, braga, 2009, p. 77-81.

SOUZA, A. O. PEREZ FILHO, A. Análise das Densidades de Drenagem e de Lineamentos como Subsídio aos Estudos Neotectônicos na Bacia do Ribeirão Araquá - SP. XI ENCONTRO NACIONAL ANPEGE. A Diversidade da Geografia Brasileira: Escalas e Dimensões da Análise e da Ação, 2015. p. 6671. 